\title{
General practitioners' use of computers for prescribing and electronic health records: results from a national survey
}

\author{
D Keith Mclnnes, Deborah C Saltman and Michael R Kidd
}

$\mathrm{R}$ eports of problems with quality of care and patient safety usually describe inpatient settings, ${ }^{1}$ but as many as one in 10 general practice patients experienced an adverse drug event in the past 6 months. ${ }^{2}$ Health information technology (HIT) has been proposed as an important strategy to combat medical errors and quality-of-care deficits. ${ }^{3}$

The Australian Government has made HIT a cornerstone of efforts to improve health-care quality, safety, and efficiency, especially in general practice. In the late 1990s, incentives were provided to general practices to install computers and clinical software packages to be used for prescribing and transmission of clinical data. ${ }^{4}$ That initiative was at least partially responsible for the rise in the use of computers by general practitioners, from 15\% in 1997 to $70 \%$ in $2000 .{ }^{5}$ Other government projects are addressing other aspects of HIT, such as standards and interconnectivity. ${ }^{6}$

Since a 2001 survey of general practices, ${ }^{7}$ there has been little description of how Australian GPs use computers in clinical care. We provide an updated view of GP computer use for a wide variety of clinical functions, especially prescribing and electronic health record functions. We studied the use of clinical computer software packages (commonly called "clinical packages") by GPs, who, following the Medicare definition of a $\mathrm{GP}^{8}$ derived at least $50 \%$ of their Medicare income from unreferred patient visits. We sought to answer two questions: Are GPs using the full range of functions available in their clinical packages?; and if not, What are possible explanations for the infrequent use of some functions, especially ones that may contribute to improved patient safety and quality of care?

\section{METHODS}

The Information Branch of the Australian Government Department of Health and Ageing provided a stratified random sample of GPs from the Medicare GP database on 5 October 2005. To be eligible for selection, GPs must have submitted at least 375 Medicare claims in the quarter ending 30 June 2005. ${ }^{9}$ From an eligible population

\section{ABSTRACT}

Objective: To describe how general practitioners use computers for clinical purposes. Design: Mail survey of a cross-sectional national stratified random sample of 3000 GPs in primary care settings between 10 October and 31 December 2005.

Main outcome measures: Use of computers, and use of computerised clinical functions such as prescribing, medication checking, generating health summaries, running recall systems, and writing progress notes.

Results: Of 1186 GPs responding (39.5\% response rate), $90 \%$ used a clinical software package. GPs used clinical packages for prescribing (98\%), checking for drug-drug interactions (88\%), recording a reason for prescribing $(65 \%)$, to order laboratory tests (85\%), run recall systems (78\%), and record progress notes (64\%). Less frequently used functions included generating lists of patients needing vaccines (43\%) and taking the same medication (39\%). Less than $20 \%$ of GPs who used a clinical package accessed computerised information during the consultation.

Conclusions: Australian general practice has achieved near-universal clinical computerisation. Electronic prescribing alone has probably improved efficiency and quality of care, and reduced medication errors. Increasing the use of other functions, such as accessing online decision support and maintaining registries of patients, is likely to lead to further health gains, especially in managing chronic conditions.

MJA 2006; 185: 88-91

of 18172 GPs, a stratified sample of 3000 was selected, consisting of $70 \%$ urban/ regional GPs and 30\% rural/remote GPs (we oversampled rural/remote areas to allow statistical comparisons between rural/remote and urban/regional GPs, but did not make such comparisons in this study). For this study, urban/regional was defined as Rural, Remote and Metropolitan Area categories 1-3, and rural/remote as categories $4-7 .{ }^{10}$

\section{Questionnaire}

We developed the survey questionnaire after reviewing the literature and interviewing experts in such fields as general practice, information technology, ${ }^{11,12}$ patient safety, ${ }^{13,14}$ quality of care, ${ }^{15}$ ease of use and usefulness of computers, ${ }^{16}$ and barriers to, and facilitators of, greater use. ${ }^{17}$

We assessed electronic health record functions with 10 items that had four response options for how a clinical function was performed: (i) mostly by computer; (ii) mostly by paper; (iii) combination of computer and paper; and (iv) did not do this task. We had six medication-related items: (i) electronic prescribing; (ii) checking drug-drug interactions; (iii) checking drug-disease interactions; (iv) checking drug allergies; (v) updating patient medication lists; and (vi) recording reason for prescribing. These items had four response options: (i) most of the time; (ii) some of the time; (iii) no (did not use the clinical package for this function); and (iv) not available on my clinical package. For this study, electronic prescribing refers to entering the prescription into a computer and printing it for the patient. Three items asked about computerised lists of patients: (i) with a specific condition; (ii) taking the same medication; and (iii) needing one or more vaccines. These had yes or no response options. Finally, three decisionsupport questions asked whether doctors used electronic information during the consultation to: (i) review guidelines; (ii) review information on medications; and (iii) assess risk factors. These had response options of most, some, or none of my consultations.

We tested a draft questionnaire with six GPs who discussed their responses and identified confusing or redundant items. A near-final version was pilot tested with a further 10 GPs. The final questionnaire included 86 items and took about 15 minutes to complete. 


\section{Data collection}

We sent the GPs a covering letter, the questionnaire and a reply-paid envelope. This was followed 3 weeks later with a repeat mailing to non-respondents. We publicised the study before each mailing in three GP bulletins: the Australian Divisions of General Practice newsletter, the Australian Medical Association newsletter, and the Royal Australian College of General Practitioners (RACGP) newsletter. No financial or educational incentives were provided to participants. We collected data between 10 October and 31 December 2005.

\section{Statistical analysis}

Descriptive analyses consisted of frequency distributions and $2 \times 2$ tables. Differences between men and women were assessed with $\chi^{2}$ tests and $t$ tests. Analyses were done with Stata software, version 9.1 (StataCorp, College Station, Tex, USA).

\section{Ethical and other approvals}

The study was approved by the RACGP National Research and Evaluation Ethics Committee, the University of Sydney Human Research Ethics Committee, the Statistical Clearing House of the Australian Bureau of Statistics, and the Medical and Pharmaceutical Services Division of the Australian Government Department of Health and Ageing.

\section{RESULTS}

Of the 3000 GPs in the sample, 1186 returned completed questionnaires, giving a response rate of $39.5 \%$. Our sample had a similar sex distribution to that in the Medicare database of 18172 GPs in active practice, but there were modest differences in age, location of medical training, and state in which practices were located (Box 1). The significant difference between our respondents and the Medicare GP database for practice location was the result of our stratification, which ensured that 30\% of the sample would be from rural and remote regions compared with 21\% of GPs in the Medicare database.

Most practices had the computer software and hardware to perform administrative and clinical functions, and most (78.3\%) had a high-speed internet connection (Box 2). Over half the practices (55.6\%) had received a Practice Incentives Program (PIP) payment for information technology, and nearly a third (31.5\%) had received the Broadband for Health incen-

\begin{tabular}{|c|c|c|c|}
\hline \multicolumn{4}{|c|}{$\begin{array}{l}1 \text { Characteristics of the general practitioner respondents compared with the } \\
\text { Medicare database of } 18172 \text { general practitioners }\end{array}$} \\
\hline Characteristic & Respondents & Medicare database & $P$ \\
\hline Total number & 1186 & 18172 & \\
\hline Sex* & & & 0.424 \\
\hline Female & 408 (34.4\%) & 6039 (33.3\%) & \\
\hline Age $(\text { years })^{\dagger}$ & & & 0.010 \\
\hline$\geqslant 65$ & $106(8.9 \%)$ & $1524(8.6 \%)$ & \\
\hline $55-64$ & $248(20.9 \%)$ & $3893(22.0 \%)$ & \\
\hline $45-54$ & 472 (39.8\%) & $6217(35.2 \%)$ & \\
\hline $35-44$ & $281(23.7 \%)$ & $4536(25.7 \%)$ & \\
\hline$\leqslant 34$ & $79(6.7 \%)$ & $1488(8.4 \%)$ & \\
\hline Country of medical training & & & 0.049 \\
\hline Australia & $852(71.8 \%)$ & 12560 (69.1\%) & \\
\hline Overseas & 334 (28.2\%) & $5612(30.9 \%)$ & \\
\hline Practice location & & & $<0.001$ \\
\hline Urban/regional (RRMA 1-3 10 ) & 829 (69.9\%) & $14363(79.0 \%)$ & \\
\hline Rural/remote (RRMA 4-710) & $357(30.1 \%)$ & $3809(21.0 \%)$ & \\
\hline State where practice is located & & & 0.018 \\
\hline Australian Capital Territory & $17(1.4 \%)$ & $276(1.5 \%)$ & \\
\hline New South Wales & 410 (34.6\%) & $6085(33.5 \%)$ & \\
\hline Northern Territory & $8(0.7 \%)$ & $128(0.7 \%)$ & \\
\hline Queensland & $220(18.5 \%)$ & $3510(19.3 \%)$ & \\
\hline South Australia & $109(9.2 \%)$ & 1518 (8.4\%) & \\
\hline Tasmania & $48(4.0 \%)$ & 472 (2.6\%) & \\
\hline Victoria & 255 (21.5\%) & 4532 (24.9\%) & \\
\hline Western Australia & 119 (10.0\%) & 1651 (9.1\%) & \\
\hline
\end{tabular}

tive payment. Nearly $90 \%$ of GPs reported they use the computerised clinical package.

Virtually all GPs who used a clinical package reported regularly using electronic prescribing (98\%), and high percentages also updated medication lists, checked for drug-drug interactions, and checked for drug allergies (Box 3A). Smaller percent- ages checked drug-disease interactions and recorded their reason for prescribing.

The most commonly used electronic health record functions were ordering laboratory tests, updating patient allergy information, and generating patient health summaries, all used by $83 \%$ or more of the GPs who used a clinical package (Box 3B). Less commonly used functions were creat-

\begin{tabular}{|lccc|}
\hline \multicolumn{3}{|l}{ Computerisation of practices reported by $\mathbf{1 1 8 6}$ general practitioners } \\
& Yes & No & Don't know \\
\hline Computer hardware and software in practice & & & \\
Computerised billing & $86.6 \%$ & $13.0 \%$ & $0.3 \%$ \\
Computerised appointment scheduling & $78.1 \%$ & $21.4 \%$ & $0.5 \%$ \\
High-speed internet connection (eg, broadband) & $78.3 \%$ & $17.8 \%$ & $3.9 \%$ \\
Dial-up internet connection & $35.3 \%$ & $57.0 \%$ & $7.8 \%$ \\
Computerised clinical package & $91.9 \%$ & $7.7 \%$ & $0.3 \%$ \\
Incentive payments received by practice & & & \\
Information technology Practice Incentives Program payment & $55.6 \%$ & $13.9 \%$ & $30.5 \%$ \\
Broadband for Health incentive payment & $31.5 \%$ & $28.8 \%$ & $39.8 \%$ \\
Use of computer for clinical purposes & $89.5 \%$ & $10.5 \%$ & 0 \\
\hline
\end{tabular}




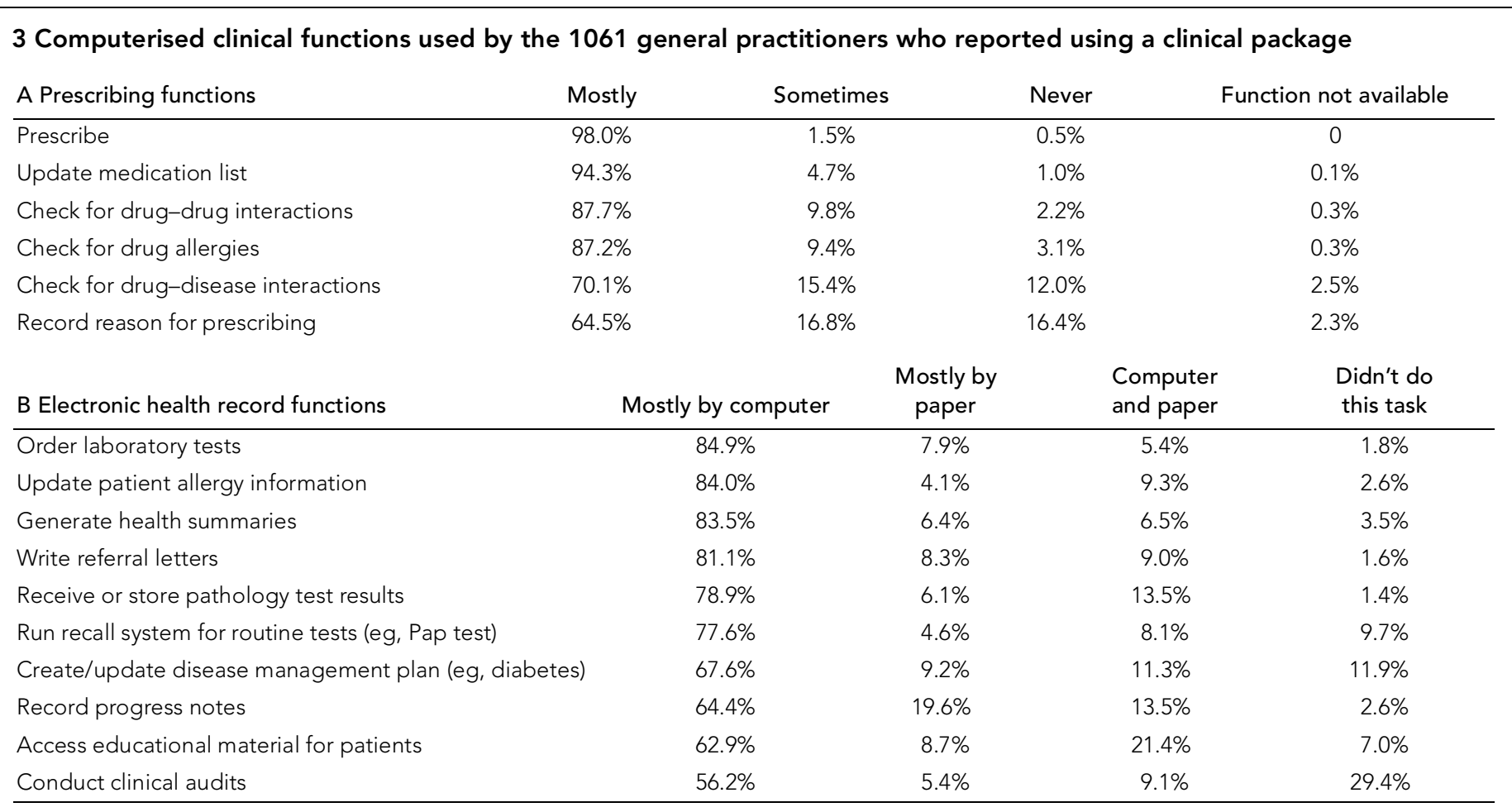

Pap = Papanicolaou.

\section{Use of computerised patient lists}

Patients with a specific condition

Patients taking the same medication

Patients needing one or more vaccines
D Access computerised information during consultations

Review prescribing information where knowledge changes often

Assess risk factors (eg, cardiovascular risk)

Review chronic disease guidelines (eg, diabetes)

\begin{tabular}{ccc} 
Yes & No & Function not available \\
\hline $58.3 \%$ & $30.4 \%$ & $11.3 \%$ \\
$39.1 \%$ & $40.8 \%$ & $20.1 \%$ \\
$42.7 \%$ & $27.4 \%$ & $29.9 \%$
\end{tabular}

(E) Brand of clinical package

\begin{tabular}{lr}
\hline Medical Director & $73.1 \%$ \\
IBA Health & $6.7 \%$ \\
MedTech & $6.4 \%$ \\
Genie & $3.5 \%$ \\
Monet & $2.7 \%$ \\
Best Practice & $2.2 \%$ \\
Other & $5.4 \%$
\end{tabular}

ing and updating disease management plans, recording progress notes, accessing educational material for patients, and conducting clinical audits.

Patient lists, or registries, which are especially important for managing chronic conditions, ${ }^{18}$ were used relatively less often (58\% or fewer of GPs who used clinical packages; Box 3C). Also, while GPs frequently used the automatic alerts for medication safety (eg, drug-drug interactions), they did not regularly use optional electronic decision-support functions during the consultation, such as review of prescribing information or assessment of risk factors (Box 3D). Among GPs using a clinical package, Medical Director was used by 73.1\% (Box 3E).

Women used prescribing functions more often than men, though the difference was statistically significant only for drug-drug interaction checking (92.3\% v 85.1\%; P= $0.001)$. Similarly, women tended to use electronic health record functions, such as ordering laboratory tests (88.9\% v 82.6\%; $P=0.007)$ and running recall systems $(81.6 \%$ v $75.4 \% ; P=0.02)$, more often than men. In contrast, men were the more frequent users of computers for generating lists of patients for all three items: patients with a specific condition (61.7\% v 52.4\%; $P=0.004)$, taking the same medication (42.7\% v 32.7\%; $P=0.002)$, and needing vaccination $(45.0 \% \mathrm{v} 38.6 \% ; \quad P=0.05)$. Men were also somewhat more likely to access computerised information during the consultation, though the difference was statistically significant only for reviewing prescribing information $(79.0 \% \mathrm{v} 73.5 \%$; $P=0.04)$.

\section{DISCUSSION}

Computerisation in Australian general practice has grown, with $90 \%$ of GPs now using a computerised clinical package. While prescribing is the most commonly used electronic function (98\% of those who use a clinical package), medication safety functions, such as checking drug-drug interactions, are also frequently used. GPs also reported widespread use of electronic health record functions, including ordering laboratory tests (85\%), updating allergy information ( $84 \%)$, and generating health summaries (84\%). These results reflect significant progress since 2001, when, among GPs in computerised practices, $71 \%$ used electronic prescribing and $42 \%$ generated health summaries electronically. ${ }^{7}$ Comparable data on the percentage of GPs using a 
clinical package was not available in the 2001 study, although $86 \%$ of general practices had a computer at that time.

There are some notable gaps in the use of certain electronic clinical functions. Among doctors using clinical packages, only $65 \%$ regularly record electronically the reason for prescribing a medication. Similar percentages electronically record progress notes $(64 \%)$ or access patient educational material (63\%). Of GPs who use a clinical package, $43 \%$ use a computerised list of patients needing vaccines, and under $40 \%$ use a computerised list of patients taking the same medication. Yet, these less-used functions have been shown to improve the management of chronic illness, as well as more acute conditions. ${ }^{19}$ Finally, having up-todate, research-based information to help with decision making has the potential to eliminate errors and improve the quality of care. $^{20,21}$

The variation in use of electronic clinical functions may be related to the functions' attributes, as suggested by diffusion theory ${ }^{22}$ and the technology acceptance model (TAM). ${ }^{16}$ Diffusion theory's "relative advantage" (ie, improvement over existing methods) may explain the near-universal use of electronic prescribing, which eliminates legibility problems and attracts PIP payments. In contrast, the lower frequency of accessing electronic information during consultations may reflect low "usefulness" (TAM term for productivity), ${ }^{16}$ so that GPs may perceive that taking even 1 or 2 minutes to seek information on the computer will reduce their productivity. The lower adoption of electronic progress notes, on the other hand, may reflect the lack of perceived "ease of use", another TAM construct. Unlike prescribing, which can be done with a few mouse clicks, most electronic progress notes require typing relatively large amounts of text, a skill that some GPs may lack.

Our study has several limitations. The $39.5 \%$ response rate may mean that the respondents were not representative of the population of Australian GPs. However, our analyses suggest that our respondents did not differ substantially on demographic and practice characteristics from the overall population of Australian GPs. Another limitation is that survey responses were selfreported, and we do not have independent verification of the computer uses reported by GPs.

Further work is necessary to examine whether GP reports of information technol- ogy use match their actual use. Also, the differences we found in use between men and women could be explored through inperson interviews and focus groups.

In conclusion, Australian general practice has achieved near-universal computerisation in less than 10 years. Electronic prescribing alone is likely to have improved efficiency and quality of care, and reduced medication errors. Improving adoption of other electronic functions is likely to lead to additional health gains, especially in managing chronic conditions.

\section{ACKNOWLEDGEMENTS}

We thank the GPs who completed the questionnaires, Geraldine Card who managed survey administration, Alex Dolezal of the Central Sydney Division of General Practice for his insights on GP perceptions and uses of computers, and the Information Branch of the Australian Government Department of Health and Ageing for supplying the GP sample frame data. David Bates and Steven Simon of Harvard Medical School generously shared survey instruments and advice. D K Mclnnes was a Packer Policy Fellow supported by Consolidated Press Holdings Ltd, the Australian Government Department of Health and Ageing, and the Commonwealth Fund of New York.

\section{COMPETING INTERESTS}

None identified.

\section{AUTHOR DETAILS}

D Keith Mclnnes, MS, Project Director ${ }^{1}$ Deborah C Saltman, AM, MD, FRACGP, FAFPHM, Professor of General Practice ${ }^{2}$ Michael R Kidd, MD, FRACGP, Professor and Head, Discipline of General Practice ${ }^{2}$

1 Department of Health Care Policy, Harvard

Medical School, Boston, MA, USA.

2 University of Sydney, Sydney, NSW.

Correspondence:

mcinnes@hcp.med.harvard.edu

\section{REFERENCES}

1 Institute of Medicine. To err is human: building a safer health system. Washington DC: National Academy Press, 2000.

2 Miller GC, Britt HC, Valenti L. Adverse drug events in general practice patients in Australia. Med J Aust 2006; 184: 321-324.

3 Institute of Medicine. Crossing the quality chasm. Washington DC: National Academy Press, 2001.

4 Australian Government Medicare Australia. Health Care Providers. Practice incentives program (PIP). Available at: http://www.medicareaustralia.gov.au/providers/incentives_ allowances/pip.htm (accessed Mar 2006).

5 Kidd MR, Mazza D. Clinical practice guidelines and the computer on your desk. Med J Aust 2000; 173: 373-375.
6 National E-Health Transition Authority. Cornerstones of e-health given green light. Available at: http://www.nehta.gov.au/content/view/98/ 144/ (accessed Apr 2006).

7 Western MC, Dwan KM, Western JS, et al. Computerisation in Australian general practice. Aust Fam Physician 2003; 32: 180-185.

8 Australian Government Department of Health and Ageing. General practice in Australia: 2004. Available at: http://www.health.gov.au/ internet/wcms/publishing.nsf/Content/pcdpublications-gpinoz2004 (accessed Jun 2006).

9 Australian Institute of Health and Welfare. Australia's health 2004: The ninth biennial health report of the Australian Institute of Health and Welfare. Canberra: AlHW, 2004. (AlHW Catalogue No. AUS 44.)

10 Australian Institute of Health and Welfare. Rural, regional and remote health: a guide to remoteness classifications. Canberra: AlHW, 2004. (AlHW Catalogue No. PHE 53.)

11 Committee on Data Standards for Patient Safety. Key capabilities of an electronic health record system: letter report. Washington DC: The National Academies Press, 2003.

12 Bell DS, Marken RS, Meili RC, et al. Recommendations for comparing electronic prescribing systems: results of an expert consensus process. Health Aff (Millwood) 2004 Jan-Jun; Suppl Web Exclusives: W4-305-317.

13 Bhasale A. The wrong diagnosis: identifying causes of potentially adverse events in general practice using incident monitoring. Fam Pract 1998; 15: 308-318.

14 Makeham MA, Dovey SM, County M, Kidd MR. An international taxonomy for errors in general practice: a pilot study. Med J Aust 2002; 177: 68-72.

15 Kawamoto K, Houlihan CA, Balas EA, Lobach DF. Improving clinical practice using clinical decision support systems: a systematic review of trials to identify features critical to success. BMJ 2005; 330: 765.

16 Davis FD, Bagozzi RP, Warshaw PR. User acceptance of computer technology: a comparison of two theoretical models. Management Sci 1989; 35: 982-1003.

17 Ahearn MD, Kerr SJ. General practitioners' perceptions of the pharmaceutical decisionsupport tools in their prescribing software. Med $J$ Aust 2003; 179: 34-37.

18 Wagner EH, Austin BT, Davis C, et al. Improving chronic illness care: translating evidence into action. Health Aff (Millwood) 2001; 20: 64-78.

19 Mitchell E, McConnahie A, Sullivan F. Consultation computer use to improve management of chronic disease in general practice: a before and after study. Inform Prim Care 2003; 11: 61-68.

20 National Electronic Decision Support Taskforce. Electronic decision support for Australia's health sector. 2003. Available at: http:// www.ahic.org.au/downloads/nedsrept.pdf (accessed Jun 2006).

21 General Practice Computing Group. Strategic framework for IM \& IT in general practice 2001 2005. Canberra: General Practice Computing Group, 2001

22 Rogers EM. Diffusion of innovations. 5th ed. New York: Free Press, 2003.

(Received 1 May 2006, accepted 13 Jun 2006) 口 